\title{
Assessment of glutathione S-transferaseM1 (GSTM1) and its polymorphisms GSTM1 null in the response to treatment with chemotherapy in advanced ovarian carcinoma
}

\author{
Avaliação da glutationaS-transferaseM1 (GSTM1) e seu polimorfismo GSTM1 nulo na resposta \\ ao tratamento com quimioterapia do câncer avançado de ovário
}

\author{
Gilberto Kendi Takeda ${ }^{1}$, Daniela Batista Leite ${ }^{2}$, Michele Gilvana Junqueira², Luiz Augusto Freire Lopes ${ }^{3}$, Ismael Dale \\ Cotrim Guerreiro da Silva ${ }^{4}$, Fausto Farah Baracat ${ }^{5}$
}

\begin{abstract}
Objective: To assess if the genotype of the glutathione S-transferase M1 (GSTM1) enzyme and its GSTM1 null polymorphism can influence the response to chemotherapeutic treatment of advanced ovarian cancer. Methods: Case-control study of 112 patients with advanced ovarian cancer submitted to chemotherapy during the period from January 1995 to December 2005. The tissue to study the GSTM1 genotype and its deletion came from surgical staging to treat ovarian cancer. The PCR product generates two distinct genotypes, characterized as positive and null. The response to chemotherapy was evaluated using the World Health Organization (WHO) criteria. Patients were classified as having: a) no response, b) a response. Results: The presence of GSTM1 or its GSTM1 null polymorphism did not influence the preoperative chemotherapy response. Among the patients who did respond, $88.9 \%$ presented with positive GSTM1 and $11.1 \%$ with null GSTM1. Among the patients that did not respond, $85.71 \%$ presented with positive GSTM1 and $14.29 \%$ with null GSTM1 $(p=0.825)$. GSTM1 and its GSTM1 null polymorphism had no influence on the postoperative response to chemotherapy. Among the patients who did respond, $80.65 \%$ presented with positive GSTM1 and $19.35 \%$ with null GSTM1. Among the patients who did not respond, $87.50 \%$ presented with positive GSTM1 and $12.5 \%$ with the null polymorphism $(p=0.553)$. Conclusion: No difference was observed in the response to treatment with chemotherapy in patients with advanced ovarian cancer, as to the GSTM1 genotype compared to its GSTM1 null polymorphism.
\end{abstract}

Keywords: Ovarian neoplasms/drug therapy; Polymorphism, genetic; Glutathione transferase

\section{RESUMO}

Objetivo: Avaliar se o genótipo da enzima glutationa S-transferase M1 (GSTM1) e seu polimorfismo GSTM1 nulo podem influenciar na resposta ao tratamento quimioterápico do câncer avançado de ovário. Métodos: Estudo caso-controle de 112 pacientes portadoras de câncer avançado de ovário, submetidas a tratamento por quimioterapia no período de Janeiro de 1995 a Dezembro de 2005. 0 tecido para estudo do genótipo da GSTM1 e sua deleção foram provenientes do estadiamento cirúrgico para tratamento do câncer de ovário. 0 produto do PCR gera dois genótipos distintos, sendo caracterizado como positivo e nulo. A resposta à quimioterapia foi avaliada usando os critérios da Organização Mundial da Saúde. As pacientes foram classificadas em: a) sem resposta, b) com resposta. Resultados: A presença da GSTM1 ou seu polimorfismo GSTM1 nulo não influenciou na resposta à quimioterapia pré-operatória. Dentre as pacientes que responderam $88,9 \%$ apresentavam GSTM1 e $11,1 \%$ GSTM1 nulo. Dentre as pacientes que não responderam $85,71 \%$ apresentavam GSTM1 e $14,29 \%$ GSTM1 nulo $(p=0,825)$. A GSTM1 e seu polimorfismo GSTM1 nulo não tiveram influência na resposta à quimioterapia pós-operatória. Dentre as pacientes que responderam 80,65\% apresentavam GSTM1 e 19,35\% nulo. Dentre as pacientes que não responderam, $87,50 \%$ apresentavam GSTM1 e

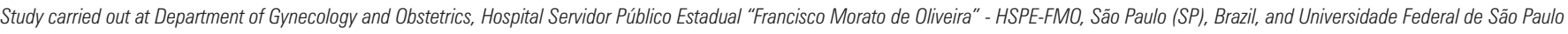
- UNIFESP - São Paulo (SP), Brazil

1 Department of Gynecology and Obstetrics, Hospital Servidor Público Estadual "Francisco Morato de Oliveira" - HSPE-FMO, Sao Paulo (SP), Brazil.

${ }^{2}$ Molecular Gynecology Laboratory, Department of Gynecology, Escola Paulista de Medicina, Universidade Federal de São Paulo - UNIFESP, São Paulo (SP), Brazil.

${ }^{3}$ Department of Pelvic Oncology, Hospital do Servidor Público Estadual "Francisco Morato de Oliveira" - UNIFESP, Sao Paulo (SP), Brazil.

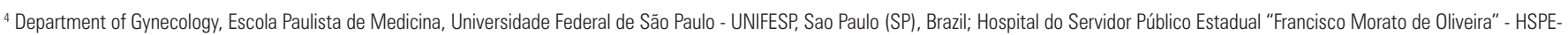
FMO, Sao Paulo (SP), Brazil.

${ }^{5}$ Department of Gynecology, Hospital do Servidor Público Estadual “Francisco Morato de Oliveira"- HSPE-FMO, Sao Paulo (SP), Brazil.

Corresponding author: Hospital do Servidor Público Estadual, Rua Pedro de Toledo, 1800, $4^{0}$ andar, Ginecologia - Vila Clementino - CEP $04039-901$ - São Paulo (SP) - Brasil - Tel.: (11) 5088-8501 -

E-mail: gktakeda@uol.com.br

Received on: Sep 2, 2010 - Accepted on: Aug 9, 2011

Conflict of interest: none
} 
$12,5 \%$ nulo ( $p=0,553)$. Conclusão: Não foi observada diferença na resposta ao tratamento com quimioterapia em pacientes com câncer avançado de ovário, em relação ao genótipo GSTM1 comparado ao seu polimorfismo GSTM1 nulo.

Descritores: Neoplasias ovarianas/quimioterapia; Polimorfismo genético; Glutationatransferase

\section{INTRODUCTION}

In the United States, the estimate for 2010 is of 21,880 new cases of ovarian cancer, with 13,850 deaths, as per the National Cancer Institute ${ }^{(1,2)}$. In Brazil, according to data of the Instituto Nacional do Câncer (INCA), the estimate was of 3837 new cases of ovarian cancer for the year 2009. The estimated number of deaths in 2008 was 2836. INCA places ovarian neoplasms as those with a low incidence. It is estimated that in Brazil this type corresponds to about 2 to $3 \%$ of cancers in females ${ }^{(3)}$.

Ovarian cancer is the most lethal among gynecological malignant tumors, and it is asymptomatic and difficult to detect during early stages. Approximately $62 \%$ of cases are diagnosed when the disease is already disseminated, and the 5 -year survival is only $27.6 \%{ }^{(4)}$.

Standard treatment for ovarian cancer consists of complete surgical removal (cytoreduction) of the tumor, followed by platinum-based systemic chemotherapy. Numerous studies proved that the volume of the residual tumor has a great impact on the patients' prognosis. The use of preoperative chemotherapy was proposed with the intention of increasing the number of patients who would benefit from complete cytoreduction, and also of decreasing morbidity and mortality associated with larger surgeries ${ }^{(5)}$. Complete cytoreduction is the primary factor in survival of patients, followed by optimal cytoreduction, in which less than one centimeter is left in the tumor maximum diameter, although this is not always possible. When one to two centimeters (suboptimal cytoreduction) or more than two centimeters of residual tumor are left, there is no impact on the patients' survival, and in these cases, preoperative chemotherapy is chosen, followed by surgery aiming to completely removing the tumor $^{(6,7)}$. The standard chemotherapy regimen used after primary cytoreduction is a combination regime of cisplatin with cyclophosphamide, and for preoperative chemotherapy, it is the combination of cisplatin and paclitaxel $^{(8,9)}$. One of the strategies to achieve a better survival in these patients would be the choice of an effective chemotherapy drug for treatment. Genetic characteristics may contribute to predicting response to chemotherapy treatment ${ }^{(10)}$.
Glutathione S-transferase (GST) may act in catalyzing the inactivation of chemotherapy agents by its conjugation with glutathione (GSH), the most abundant antioxidant in the intracellular compartment $^{(11)}$.

Glutathione S-transferase $m u-1$ (GSTM1) is a polymorphic member of the gene class $m u$ of the GST family, and the GSTM1 null allele is the result of the deletion of 15 kilobases $(\mathrm{Kb})$, which does not have the same activity as GSTM1 ${ }^{(12)}$.

Resistance to chemotherapy represents one of the most important causes of treatment failure in patients with ovarian cancer. There is evidence that individuals with the null polymorphic GSTM1 gene may have greater survival ${ }^{(13)}$.

\section{OBJECTIVE}

This project intended to evaluate if the GSTM1 genotype and its GSTM1 null polymorphism can influence the response to chemotherapy treatment.

\section{METHODS}

A retrospective case-control study was conducted of 112 patients with advanced epithelial ovarian cancer, who required chemotherapy during the period from January 1995 to December 2005, at the Department of Gynecology and Obstetrics - HSPE-FMO. This study was approved by the Research ethics Committee of the institution (no. 0121/06).

The material for the genotype study of GSTM1 and its deletion was obtained from the archives of the Anatomopathology Department of the Hospital Servidor Público Estadual "Francisco Morato de Oliveira" (HSPE-FMO). A total of ten one-micron slices were made in paraffin-blocked specimens, obtained for surgical staging of ovarian cancer. The study of the GSTM1 genotype and its deletion was performed at the Laboratory of Molecular Gynecology of the Department of Gynecology, Escola Paulista de Medicina - Universidade Federal de São Paulo (UNIFESP). The tissue was deparaffinized and the deoxyribonucleic acid (DNA) was extracted as per the Kit (Qiagen, Chatworth, CA) protocol. Polymerase chain reactions (PCR) were performed to analyze the polymorphism of GSTM1.

The reactions were processed in a final volume of $25 \mathrm{~mL}$, containing $1 \mathrm{~mL}$ of each primer (initiator, oligonucleotide) (10 pmol/mL), $2 \mathrm{~mL}$ of genomic DNA $(100 \mathrm{ng} / \mathrm{mL}), 10 \mathrm{~mL}$ of PCR Master Mix (Promega, Madison, USA) (50 U/mL Taq DNA Polymerase, $400 \mathrm{mM}$ dNTP, $3 \mathrm{mM} \mathrm{MgCl}$ ) and $12 \mathrm{~mL}$ of distilled water. The reactions were incubated in a thermocycler 
(Gene amp PCR System 9700-Perkin Elmer) under the following conditions: first stage of the cycle (denaturation) : the temperature was elevated to 95 ${ }^{\circ} \mathrm{C}$ during 5 minutes, followed by 40 cycles at $94{ }^{\circ} \mathrm{C}$, for 60 seconds; second stage (annealing) the temperature was reduced to $55{ }^{\circ} \mathrm{C}$ for 60 seconds, and during the last stage of the cycle (DNA strip extension), the temperature was elevated to $72^{\circ} \mathrm{C}$ for 60 seconds, finalizing with incubation at $72{ }^{\circ} \mathrm{C}$, for 10 minutes.

The products of the reactions were analyzed in 2\% agarose gel (Amersham Pharmacia Biotech), and stained with ethidium bromide.

Since GSTM1 polymorphism could present homozygote deletion for both alleles, the use of a second initiator was needed, with the intent of obtaining internal controls indicative of the presence of DNA, as well as of the integrity of the reagents used. Therefore, a pair of oligonucleotides was added from a constitutional gene (beta-globin) to the PCR reactions.

The allele-specific initiators used were GSTM1 - 215 base pairs (1 Forward (Sense): 5' - GAA CTC CCT GAA AAG CTA AAG C - 3' and 2 Reverse (Antisense): 5'- GTT GGG CTC AAA TAT ACG GTG G - 3') and beta-globin - 268 base pairs (1 Forward (Sense): 5'- CAA CTT CAT CCA CGT TCA CC - 3' and 2 Reverse (Antisense): 5'- GAA GAG CCA AGG ACA GGT AC - 3') $)^{(14)}$.

The product of PCR generates two distinct genotypes, in which the presence of bands $268 \mathrm{pb}$ and $215 \mathrm{pb}$ evidence that the patient has the GSTM1 gene, which is characterized as positive $(+/+)$. When only band $268 \mathrm{pb}$ is visualized, which corresponds to the beta-globin, it is concluded that the GSTM1 is not present, thus, it is called null (-/-).

The response to chemotherapy was determined by the plasma levels of CA 125 and/or clinical response using the World Health Organization (WHO) criteria. The patients were classified as with no response to chemotherapy when there was disease progression or stable disease ${ }^{(15)}$.

Response to treatment was considered when it was complete or partial, and was maintained for at least four weeks.

For a comparison of the distribution of the variable age, the $t$ test was used, with the result expressed in mean, minimum, and maximum. As to race, physical examination, histological type, surgical staging, preand postoperative chemotherapy, and present or null GSTM1, the test of simple proportions was used with values expressed in percentages.

All information and results were analyzed using the Statistical Package for the Social Sciences (SPSS) 15.0 for Windows, with descriptive calculations for mean and standard deviation for quantitative variables, and frequency for qualitative variables. The categorical analysis was made using the chisquared test or Fischer's Exact test (when the variable was less than 5). Statistical significance was established as $\mathrm{p}<0.05$. The variables included were GST polymorphism (positive or null), response to preoperative chemotherapy (yes or no) and response to postoperative chemotherapy (yes or no). Cross tables were prepared between GST polymorphism versus response to preoperative chemotherapy and between GST polymorphism versus postoperative chemotherapy.

\section{RESULTS}

The age of patients varied from 18 to 86 years, with a mean of 58.34 years.

The white race was the most frequent, with $92 \%$, followed by mulatto and black, with $4 \%$ each.

Physical examination findings were: abdominal tumor: $79.4 \%$, ascitis: $13.2 \%$, and normal examination (7.4\%).

The histological types found were serous carcinoma $(66 \%)$, not otherwise specified (NOS) carcinoma $(19 \%)$, mucinous carcinoma (10\%), endometrioid carcinoma (3.5\%), and Brenner tumor $(1.5 \%)$.

The most frequent surgical stages found were IIIC $(61.6 \%)$ and IC (17\%) (Table 1).

Table 1. Surgical staging

\begin{tabular}{lcc}
\hline Variables & $\mathbf{n}$ & $\%$ \\
\hline Stage I A/B & 8 & 7.1 \\
Stage IC & 19 & 17 \\
Stage II A/B & 8 & 7.1 \\
Stage II C & 1 & 0.9 \\
Stage III A/B & 2 & 1.8 \\
Stage III C & 69 & 61.6 \\
Stage IV & 5 & 4.5 \\
\hline
\end{tabular}

Preoperative chemotherapy was performed in 42 patients (37.5\% of the cases), in which $22(52.4 \%)$ responded and $20(47.6 \%)$ had no response.

Postoperative chemotherapy was performed in 91 patients ( $81.3 \%$ of the cases), in which $58(63.7 \%)$ responded and $33(36.3 \%)$ did not respond.

Glutathione S-transferase M1 (GSTM1) was found in 60 patients $(53.6 \%)$, and was null in nine $(15 \%)$ and positive in $51(85 \%)$.

Among the patients that responded to preoperative chemotherapy, $11.1 \%$ presented with null GSTM1 and $88.9 \%$ with positive GSTM1. Among the patients that 
did not respond to preoperative chemotherapy, $14.29 \%$ presented with null GSTM1 and $85.71 \%$ with positive GSTM1, $(\mathrm{p}=0.825)$ (Table 2).

Table 2. Response to preoperative chemotherapy as to GSTM1 and its null polymorphism

\begin{tabular}{|c|c|c|c|}
\hline $\begin{array}{l}\text { Response to } \\
\text { preoperative CT }\end{array}$ & Null GSTM1 (\%) & GSTM1 (\%) & Tota \\
\hline No & $2(14.29)$ & $12(85.71)$ & 14 \\
\hline Yes & $1(11.1)$ & $8(88.9)$ & 9 \\
\hline Total & 3 & 20 & 23 \\
\hline
\end{tabular}

For statistical analysis, Pearson two-tailed chi-squared test and Fisher exact test: $p=0.825$ and $p=1.000$. CT: chemotherapy; GSTM1: glutathione S-transferase mu 1.

Among the patients that responded to postoperative chemotherapy, in $80.65 \%$ GSTM1 was positive and in $19.35 \%$, null. Among the patients that did not respond to postoperative chemotherapy, in $87.5 \%$, GSTM1 was positive and in $12.5 \%$, it was null $(\mathrm{p}=0.553)$ (Table 3).

Table 3. Response to postoperative chemotherapy as to glutathione S-transferase $m u 1$ and its glutathione $\mathrm{S}$-transferase $m u 1$ null polymorphism.

\begin{tabular}{lccc}
\hline $\begin{array}{l}\text { Response to } \\
\text { postoperative CT }\end{array}$ & Null GSTM1 (\%) & GSTM1 (\%) & Total \\
\hline No & $2(12.5)$ & $14(87.5)$ & 16 \\
Yes & $6(19.35)$ & $25(80.65)$ & 31 \\
\hline Total & 8 & 39 & 47 \\
\hline
\end{tabular}

For statistical analysis, Pearson chi-squared test and Fisher exact test (two-tailed): $p=0.553$ and $p=0.697$, respectively.

CT: chemotherapy; GSTM1: glutathione S-transferase mu 1.

\section{DISCUSSION}

Drug biotransformations, especially those processed in the liver are often grouped into two phases. During phase one, generally carried out by the cytochrome P-450 (CYP) enzymes, which include reactions of oxidation, reduction or hydrolysis, drugs may be activated, inactivated, or unchanged in their activities. During phase two, which involves conjugation reactions, there is almost always total inactivation of the xenobiotic, which is generally carried out by enzymes GSTs and $\mathrm{N}$-acetyltransferases (NATs). The presence of polymorphisms in these genes modifies enzymatic activity, leading to less efficacy in detoxification of reactive compounds and may be involved in ovarian carcinogenesis. The effect of GST in chemotherapy treatment is contrary to what is found in susceptibility to ovarian cancer, since the detoxification of the chemotherapy agents could diminish their efficacy. The presence of polymorphism in these genes could potentiate the response to treatment with chemotherapy drugs ${ }^{(16,17)}$.

Glutathione S-transferase (GST) catalyzes the detoxification of glutathione (GSH) dependent on electrophilic xenobiotics and of certain products of oxidation stress, and are, therefore, critical in cellular homeostasis. There are two families of GST: the cytosolic (soluble) GST family, that includes classes alpha, kappa, mu, omega, pi, sigma, theta, and zeta, and the second, microsomal GST family ${ }^{(18,19)}$.

GSTM1 belongs to the $m u$ class and is located in locus 1p13-3. This gene is polymorphic, with alleles GSTM1a and GSTM1b, which differ by the substitution of a single pair of bases. The null GSTM1 has a deletion in the gene that codes GSTM1 so that it does not present proteic expression and enzymatic activity is absent ${ }^{(17)}$.

Genetic polymorphism is easily determined in population studies using DNA isolated from histopathological archives of blood or tissues. These polymorphisms offer the tool that can be used in epidemiological studies to explore hypotheses that GSTs possess a determining role in the individual response to chemical carcinogenics and chemotherapy agents.

Resistance to chemotherapy represents one of the most important causes in treatment failure of patients with ovarian cancer. The glutathione S-transferase (GSTM1, GSTP1, and GSTT1) polymorphism has been implied in the resistance to chemotherapy and in survival of patients with cancer of the ovary ${ }^{(11)}$.

Survival in cases of ovarian cancer is low. Treatment consists of surgery, with the attempt to remove the entire tumor or to leave less than $1 \mathrm{~cm}$ of residual tumor followed by platinum-based chemotherapy ${ }^{(20)}$.

Despite the fact that the residual disease is an important prognostic factor, some patients who underwent optimal cytoreduction acquired resistance to chemotherapy and experienced low rates of survival. On the other hand, there is a minority of patients whose tumor was not entirely removed as would be ideal (residual tumor larger than $1 \mathrm{~cm}$ ) and who responded well to chemotherapy treatment, with no relapses ${ }^{(21)}$.

The response to treatment for ovarian cancer is variable and may be attributed, in part, to variations of genetic polymorphism that may influence the metabolism of drugs, such as glutathione S-transferase $\mathrm{M} 1, \mathrm{~T} 1$, and $\mathrm{P} 1^{(22)}$.

Therefore, it has been suggested that the high activity of GST may result in rapid metabolization, diminishing the cytotoxic effects of the chemotherapy agents on the tumor, leading to an unsatisfactory response to treatment and a shortened survival ${ }^{(10)}$.

Some studies have reported benefits from the polymorphic genotypes of GSTs with responses to chemotherapy ${ }^{(13,22)}$.

Nagle et al. studied 454 patients with epithelial cancer of the ovary and observed improved survival when polymorphisms GSTP1, GSTT1, and GSTM1 were present ${ }^{(13)}$. 
Medeiros et al. studied 24 patients with cancer of the ovary treated with surgical cytoreduction and postoperative chemotherapy with paclitaxel and cisplatin and verified that there was no statistical difference as to survival, but there was an improvement in the mean survival and disease-free interval in the group with null GSTM1 and null GSTT1 polymorphisms ${ }^{(22)}$.

However, other studies have not demonstrated a difference in response to chemotherapy in cases of ovarian cancer in patients with the GST genotype when compared to the polymorphic GST ${ }^{(10,12)}$.

Beeghly et al. assessed 215 patients with epithelial cancer of the ovary as to the genotypes GSTM1, GSTT1, and GSTP1, and their polymorphisms, and there was no correlation with the response to chemotherapy treatment with cisplatin, carboplatin, paclitaxel, or cyclophosphamide ${ }^{(10)}$.

Lallas et al. evaluated 146 patients with epithelial ovarian cancer relative to the GSTM1 genotype and its null GSTM1 polymorphism and observed no influence on the response to chemotherapy treatment ${ }^{(12)}$.

In one study, the patients presenting with combined null GSTM1 and null GSTT1 polymorphisms displayed the worst response to chemotherapy treatment ${ }^{(23)}$.

Howells et al. evaluated 78 patients with epithelial carcinoma of the ovary treated with chemotherapy and observed that the patients with combination null GSTM1 and null GSTT1 were associated with a poor response to chemotherapy treatment ${ }^{(23)}$.

\section{CONCLUSION}

In the results of the present study, no action of GSTM1 compared to its null GSTM1 polymorph was observed in the response to chemotherapy treatment of advanced ovarian cancer.

\section{REFERENCES}

1. Jemal A, Siegel R, Xu J, Ward E. Cancer Statistics 2010. CA Cancer J Clin. 2010;60(5):277-300.Erratum in CA Cancer J Clin. 2011;61(2):133-4.

2. National Cancer Institute, U.S. National institute of Health. Ovarian cancer[Internet]. [cited 2010 Dez 13]. Available from:http://www.cancer.gov/ cancertopics/types/ovarian

3. Instituto Nacional do Câncer (INCA). Ministério da Saúde. Ovário [Internet]. [citado 2010 Dez 13]. Disponível em:http://www2.inca.gov.br/wps/wcm/ connect/tiposdecancer/site/home/ovario

4. Altekruse S, Kosary C, Krapcho M, Neyman N, Aminou R, Waldron W, et al. SEER cancer statistics review, 1975-2007.National Cancer Institute Betehesda, MD. [cited 2011 Sep 22]. Available from: http://seer.cancer.gov/ csr/1975_2007/ [based on November 2009 SEER data submission posted to the SEER web site, 2010.]
5. Perlman S, Ben-Arie A. [Neoadjuvant chemotherapy for advanced ovarian cancer]. Harefuah. 2010;149(6):377-81, 402. Hebrew.

6. Pomel C, Jeyarajah A, Oram D, Shepherd J, Milliken D, Dauplat J, et al. Cytoreductive surgery in ovarian cancer. Cancer Imaging. 2007;7:210-5.

7. Bristow RE, Eisenhauer EL, Santillan A, Chi DS. Delaying the primary surgical effort for advanced ovarian cancer: a systematic review of neoadjuvant chemotherapy and interval cytoreduction. Gynecol Oncol. 2007;104(2):480-90.

8. McGuire WP, Hoskins WJ, Brady MF, Kucera PR, Partridge EE, Look KY, et al. Cyclophosphamide and cisplatin compared with paclitaxel and cisplatin in patients with stage III and stage IV ovarian cancer. N Engl J Med. 1996;334(1):1-6.

9. Piccart MJ, Bertelsen K, James K, Cassidy J, Mangioni C, Simonsen E, et al. Randomized intergroup trial of cisplatin-paclitaxel versus cisplatincyclophosphamide in women with advanced epithelial ovarian cancer: threeyear results. J Natl Cancer Inst. 2000;92(9):699-708.

10. Beeghly A, Katsaros D, Chen H, Fracchioli S, Zhang Y, Massobrio M, et al. Glutathione S-transferase polymorphisms and ovarian cancer treatment and survival. Gynecol Oncol. 2006;100(2):330-7.

11. Khrunin A, Moisseev A, Gorbunova V,Limborska S. Genetic polymorphisms and the efficacy and toxicity of cisplatin-based chemotherapy in ovarian cancer patients. Pharmacogen J. 2010;10(1):54-61.

12. Lallas T, McClain S, Shahin M, Buller R. The glutathione S-transfeaseM1 genotype in ovarian cancer. Cancer Epidemiol Biomarkers Prev. 2000;9(6):587-90.

13. Nagle C, Chenevix-Trench G, Spurdle A, Webb P. The role of glutathioneS-transferase polymorphisms in ovarian cancer survival. Eur $\mathrm{J}$ Cancer. 2007;43(2):283-90.

14. Gattás G, Soares-Vieira J. Cytochrome P450-2E1 and glutathione S-transferase mu Polymorphisms among whites and mulattos from Brazil. Occup Med (Lond). 2000;50:508-11.

15. Julka P, Doval D, Gupta S, Rath G. Response assessment in solid tumours: a comparison of WHO, SWOG and RECIST guidelines. $\mathrm{Br} J$ Radiol. 2008;81 (966):444-9.

16. Delort L, Chalabi N, Satih S, Rabiau N, KwiatkowskiF, Bignon YJ, et al. Association between genetic polymorphisms and ovarian cancer risk. Anticancer Res. 2008;28(5B):3079-81.

17. Losi-Guembarovski R, Cólus I. Glutationa S-transferase M1 (GSTM-1): distribuição étnica e relação com câncer. Semina: Ci Biol Saúde. 2001;22(1):3-9.

18. Hayes J, Flanagan J, Jowsey I. Gltutathione transferases. Annu Rev Pharmacol Toxicol. 2005;45(1):51-88

19. Dewaele M, Hannelore M, Agostinis P. ROS-mediated mechanisms of autophagy stimulation and their relevance in cancer therapy. Autophagy. 2010;6(7):838-954.

20. Guppy A, Nathan P, Rustin G. Epithelial ovarian cancer. A review of current management. Clin Oncol. 2005;17:399-411.

21. Berchuck A, Iversen E, Lancaster J, Pittman J, Luo J, Lee P, et al. Patterns of gene expression that characterize long-term survival in advanced stage serous ovarian cancers. Clin Cancer Res. 2005;11(10):3686-96.

22. Medeiros R, Pereira D, Afonso N, Palmeira C, Faleiro C, Afonso-Lopes C, et al. Platinum/paclitaxel based chemotherapy in advanced ovarian carcinoma: glutathione S-transferase genetic polymorphisms as predictive biomarkers of disease coutcome. Int J Clin Oncol. 2003:8(2):156-61.

23. Howells R, Dhar K, Hoban P, Jones PW, Fryer AA, Redman CW, et al. Association between glutathione-S-transferase GSTP1 genotypes, GSTP1 over-expression, and outcome in epithelial ovarian cancer. Int J Gynecol Cancer. 2004;14(2):242-50. 